\title{
Fintech of Financing at BPRS: a Challenge between a Legal Problem and Business Opportunity
}

\author{
Binti Nur Asiyah ${ }^{1}$, Iffatin Nur ${ }^{2}$ \\ binti.advan@gmail.com¹, iffaeltinury@gmail.com² \\ FEBI IAIN Tulungagung ${ }^{1}$, Pascasarjana IAIN Tulungagung ${ }^{2}$
}

\begin{abstract}
Financing at Bank Perkreditan Rakyat Syari'ah (BPRS) competes with other financing institutions regarding its speed in accessing customers. The speed of approaching customers is a choice since an element of financial technology (fintech) that is capable for connecting the needs of customers with Islamic banks is present. However, its existence is not without problems. This is because fintech measures the accuracy of the data provided so that there is a match between the displayed data and the customer's character, but such may raise legal problems. This study is conducted with a qualitative approach employing descriptive analysis. Data mining is done through interviews and observations both through websites and literature. The findings of this study indicate that fintech financing may become an option as a medium to bring financial institutions closer to customers and business opportunities. In order to avoid any legal problem that may arise, a direct verification process must still be carried out so as to preclude a possible risk of having unmatched attached customers' data with their characters.
\end{abstract}

Keywords: Fintech financing, BPRS, legal problem, business opportunity

\section{Pendahuluan}

Bank Pembiayaan Rakyat Syariah (BPRS) menghadapi tantangan dalam pengelolaan bisnis dari berbagai segmentasi. Segmentasi pasar ke atas berhadapan dengan bank umum syariah, unit usaha syariah, ke bawah dengan koperasi syariah, baitul maal wat tamwil. Persaingan juga dialami BPRS dengan bank umum konvensional, financial technologi (fintech) yang dikelola oleh lembaga swasta.

Bank umum syariah dan unit usaha syariah memiliki produk pembiayaan yang menyentuh unsur mikro bagi industri masyarakat. Bank Mu'amalat Indonesia (BMI) menyediakan pembiayaan KPR IB mu'amalat dengan menawarkan akad murabahah dan musyarakah mutanaqisah, pembiayaan IB mu'amalat pensiun dan IB muamalat multiguna.[1] Bank Syariah Mandiri memiliki pembiayaan terkait pembiayaan implan, pembiayaan kepada pensiunan, pembiayaan griya dan pembiayaan kendaraan bermotor.[2]

Bank konvensional menyalurkan dana kepada masyarakat melalui sumber dana murah yaitu Kredit Usaha Rakyat (KUR). Masyarakat yang memiliki usaha dan mendapatkan surat keterangan dari Desa memiliki hak untuk mengakses dana KUR pemerintah yang dilewatkan oleh bank konvensional. Tawaran bunga murah menjadi daya tarik bagi masyarakat untuk mengambil kredit di bank konvensional.

Pesaing tersebut merupakan pesaing level perbankan. Perusahaan Fintech juga menawarkan kemudahan-kemudahan dalam penyaluran dana kepada masyarakat, sehingga semakin menjadi pesaing bagi BPRS. Layanan fintech dengan mudah masuk pada android berbasis media facebook, instragram, twiter. Aspek kemudahan-kemudahan yang ditawarkan oleh lembaga fintech tak ayal menjadikan nasabah yang berfikir kecepatan untuk menjadi 
pilihan. Perusahaan fintech baik konvensional dan syariah sampai dengan 20 Desember 2019 mencapai 164 perusahaan.[3]

Perbankan dan perusahaan fintech tersebut menawarkan penyaluran dana kepada masyarakat.[4] Pembiayaan pada BPRS suatu keniscayaan untuk terus mendekatkan diri kepada masyarakat agar menjadi pilihan di tengah semua pilihan yang tersedia. Informasi cepat yang disediakan BPRS menjadi satu permasalahan dengan akurasi data yang diharapkan bisa menyentuh karakter nasabah. Paper ini mendiskusikan potensi BPRS memiliki fintech pembiayaan dengan manajemen yang dikelola oleh BPRS, sehingga mampu meminialisir risiko yang mungkin ditimbulkan.

\section{Metode}

Paper ini ditulis dengan pendekatan kualitatif dan analisis deskriptif. Paper ini mendeskripsikan kebutuhan BPRS dalam mengenalkan produk kepada nasabah dengan waktu cepat, namun tetap ramah hukum, tidak menimbulkan problem baru. Data yang digunakan adalah data sekunder yang diakses melalui observasi melalui website terkait.

\section{Pembahasan}

\subsection{Financial Technology (Fintech)}

Financial Technology merupakan jawaban atas digitalisasi keuangan pada masa perkembangan kekinian. Leong dan Sung mendefinisikan FinTech sebagai ide inovatif yang meningkatkan operasi layanan keuangan dengan memberikan solusi dengan memberikan bantuan teknologi sesuai dengan skenario bisnis dan juga sebagai ide dan model bisnis baru yang mempengaruhi seluruh ekosistem bisnis.[5] Fintech menurut Bulatova[6], Thakor[7] memiliki layanan berupa pinjaman online, transfer uang, credit rating, crowdfunding, blockchain dan cryptocurrency. Manfaat dari teknologi ini mampu meningkatkan pengembangan keuangan dan putaran ekonomi di masyarakat. Perkembangan ekonomi yang didorong oleh kemajuan teknologi akan meningkatkan pertumbuhan ekonomi masyarakat.

Kehadiran fintech menjadi suatu inovasi digital[8] dalam memberikan layanan yang bekerjasama dengan sektor keuangan. Sebagaimana dirilis oleh Baber, kehadiran fintech meningkatkan investasi Global. Ali Baba Misalnya dapat meningkatkan modal pada quarter k2 tahun 2018 sebedar 2 kali lipat yaitu \$32,2 milyar.[5] Globalisasi benar-benar menunjukkan taringnya dalam bisnis dengan memanfaatkan peran teknologi. Di Indoenesia, perkembangan fintech luar biasa. OJK mencatatkan per Desember 2019 sebanyak 164 perusahaan fintech baik syariah maupun konvensional. Berikut adalah data fintech yang berbasis syariah di Indonesia:

Table 1. Data fintech syariah di Indonesia.

\begin{tabular}{lll}
\hline Platform & Nama Perusahaan & Jenis Usaha \\
\hline Investree & PT. Investree Radhika Jaya & www.investree.id \\
Ammana & PT. Ammana Fintek Syariah & www.ammana.id \\
Dana Syariah & PT. Dana Syariah Indonesia & www.danasyariah.id \\
Danakoo & PT. Danakoo Mitra Artha & www.danakoo.id \\
Alami & PT. Alami Fintek Sharia & www.p2p.alamisharia.co.id \\
Syarfi & PT. Syarfi Teknologi Finansial & www.syarfi.id \\
Duha SYARIAH & PT. Duha Madani Syariah & www.duhasyariah.com \\
Qazwa & PT. Qazwa Mitra Hasanah & www.qazwa.id \\
bsalam & PT. Maslahat Indonesia Mandiri & www.bsalam.id \\
ETHIS & PT. Ethis Fintek Indonesia & https://ethis.co.id
\end{tabular}




\begin{tabular}{|c|c|c|}
\hline Kapital Boost & PT. Kapital Boost Indonesia & https://kapitalboost.co.id \\
\hline PAPITUPI & PT. Piranti Alpabhet Perkasa & www.papitupisyariah.com \\
\hline SYARIAH & & \\
\hline $\begin{array}{l}\text { Berkah Fintek } \\
\text { Syariah }\end{array}$ & PT. Berkah Fintek Syariah & www.finteksyariah.co.id \\
\hline
\end{tabular}

Sebanyak 13 data perusahaan fintek di atas merupakan bagian dari layanan kemudahan akses keuangan bagi masyarakat.

\subsection{Problematika Hukum pelaksanaan Fintech}

Fintech memberikan aspek cepat dalam mempertemukan suatu produk dengan calon pengguna. Pelaksanaan fintech diharapkan Bulatova et al tetap mendasarkan pada norma-norma syariah pada keuangan syariah[9]. Norma syariah menjadikan potensi masalah yang muncul dari fintech dapat terhindarkan. Pelaku bisnis menjadikan syariah sebagai acuan dalam melangkah. Fintech menurut Imaniyati mempertemukan semua pelaku bisnis dari berbagai belahan wilayah maupun dunia[10], sehingga memiliki karakter yang berbeda-beda. Karakter yang saling tidak diketahui oleh lembaga memberi peluang terjadi problem bagi keberlangsungan keuangan.

Upaya menghindari problematika yang akan timbul dengan penggunaan fintech, Wahyuni menyebutkan pentingnya untuk memastikan pelaksanaan kompilasi hukum ekonomi syariah pada pasal 21 peraturan Mahkamah Agung tahun 2008.[11] diantara dalam kompilasi hukum ekonomi syariah tersebut antara lain terkait pemenuhan asas, ikhtiyari (sukarela), amanah, kehati-hatian, tidak berubah akad, saling menguntungkan, adanya kesetaraan, transparansi, berkemampuan, kemudahan, itikad baik dan terpenuhinya unsur halal. Selama asas tersebut terpenuhi, maka potensi problem hukum akan bisa terhindarkan.

Guna mewujudkan keamanan untuk berbagai pihak, Alwi [12] dan Mujahidin [12] menyebutkan bahwa pelaksanaan layanan jasa keuangan syariah harus memperhatikan kepatuhan syariah dan perlindungan bagi pengguna layanan. Fintech dalam hal ini harus menciptkan rasa aman baik bagi BPRS maupun bagi nasabah. Mujahidin menambahkan agar rasa aman dapat dirasakan, maka perlu memastikan kesesuaian pelaksanaan dengan peraturan yang berlaku dan mengedepankan etika moral dalam berbisnis.[13]

\subsection{Peluang Bisnis Fintech Pembiayaan di BPRS}

Peluang bisnis fintech bagi pembiayaan[14] menjadi solusi bagi pengembangan nilai ekonomi Islam. Islam memiliki nilai keadilan, keadilan dan distribusi harta. Fintech menghadirkan kesempatan bagi siapapun mendapatkan informasi tentang layanan keuangan. Layanan keuangan berupa pembiayaan menjadi satu produk bank syariah. Menurut Fawzi [15], Saba, Kouser, Chau[14] bahwa fintech memberikan kemudahan, sifat praktis, menimbulkan rasa nyaman bagi pengguna, dan biaya murah. Penggunaan teknologi pada sektor keuangan memiliki payung hukum pada aturan Bank Indonesia nomor 19/12/PBI/2017 dan POJK nomor (POJK) No. 13 tahun 2018 tentang inovasi digital pada sektor layanan keuangan. Upaya penerapan prinsip syariah pada fintech telah memiliki fatwa Dewan Syariah Nasional (DSN) nomor 117/DSN-MUI/II/2018, yakni pemberian layanan jasa keuangan yang mempertemukan konsumen dengan lembaga terkait dengan fasilitas elektronik melalui jaringan internet. Fintech dalam hal ini dimaknai sebuah cara agar transaksi itu bisa terlaksana.

Firmansyah menyebutkan bahwa partisipasi fintech syariah diantaranya adalah PT.

Berkah Inovasi Nusantara, PT. Sinergi Inti Berkah, Alami, Syarfi, Qasir, dan Ethis.[16] 
Sebagaimana data perusahaan fintech tersebut sebagian tidak terdaftar pada listing OJK, artinya legalitas kelembagaan sebagian perusahaan fintech masih dipertanyakan. Dominasi konsumen perusahaan fintech terjadi pada perusahaan Qasir dan Ethis yaitu Ethis 25 ribu pelanggan, dan Qasir 5 ribu pelanggan dengan segmentasi produk yang berbeda.

Peluang pembiayaan pada BPRS dengan memanfaatkan fintech sangat besar. Hal ini menurut Fawzi, hasil risetnya mengatakan bahwa pelaksanaan fintech yang sudah ada memiliki kelemahan diantaranya belum memiliki Dewan Pengawas Syariah, sebagian belum terdaftar di OJK, adanya kekhawatiran adanya kejahatan keuangan.[17] BPRS secara kelembagaan memiliki DPS, maka potensi bisnis ini menjadi lahan bagi BPRS. Meskipun demikian ada rasa psimis yang dirasakan oleh BPRS, menurut Subekti pembiayaan yang selama ini dilakukan dengan ketemu langsung nasabah, cek langsung lapangan, potensi pembiayaan macet masih sering dirasakan.[18] Dilema ini menjadi cambuk antara potensi yang besar dan problematika yang mungkin terjadi.

Segmentasi masyarakat yang membutuhkan layanan fintech memiliki ragam sesuai dengan karakter usaha, dan kebutuhan. Firmansyah dan Ramdhani menyebutkan mahasiswa merupakan bagian dari segmen yang membutuhkan layanan keuangan dengan menggunakan akad murabahah atas kebutuhan mahasiswa.[19] Kebutuhan mahasiswa diantaranya laptop, handpone, pembayaran Uang kuliah tunggal, pembayaran kos dan pembelian buku.

\section{Kesimpulan}

Pembiayaan menjadi kebutuhan riil bagi nasabah maka diperlukan informasi yang sampai dan bisa diterima dengan cepat. Kecepatan itu mampu direspon oleh kemajuan teknologi melalui fintech. Fintech menjadi penting bagi BPRS untuk memasarkan produk pembiayaan secara luas. Jangkauan teknologi semakin memudahkan dan menjadi merata. Potensi permasalahan akibat pelaksanaan fintech pembiayaan sebuah keniscayaan, maka tetap diperlukan verifikasi data secara riil, karena fintech hanyalah sebuah cara untuk menghubungkan bank dengan nasabah. Keputusan bank untuk pemberian pembiayaan tetap menjadi keharusan dengan senantiasa menjadikan asas hukum ekonomi syariah dipatuhi.

\section{References}

[1] B. N. Asiyah, "Dampak dan Strategi Kebijakan Pengembangan Pembiayaan Dan Inklusifitas Keuangan Dalam Peningkatan Pembiayaan," J. Bisnis dan, vol. 5, no. 1, pp. 133-156, 2017.

[2] B. S. Mandiri, "Produk Pembiayaan," Bank Syariah Mandiri, 2020. [Online]. Available: https://www.mandirisyariah.co.id/\#.

[3] O. J. Keuangan, "Perusahaan Fintech," Otoritas Jasa Keuangan, 2019. [Online]. Available: http://ojk.go.id.

[4] K. Leong and A. Sung, "FinTech (Financial Technology): What is It and How to Use Technologies to Create Business Value in Fintech Way?," Int. J. Innov. Manag. Technol., vol. 9 , no. 2, 2018.

[5] E. I. Bulatova, E. A. Potapova, R. A. Fathutdinova, and R. C. Yandiev, "The Fintech and Islamic Finance Synthesis in the Modern World," Cuad. Desarro. Apl. a las TIC, no. October, pp. 258-273, 2019.

[6] A. V Thakor, "Fintech and Banking Fintech and Banking: What Do We Know ?," J. Financ. Intermediation, 2019.

[7] U. Mutiara, L. R. Candanni, and R. R. Hasibuan, "Construction of Financial Technology in Banking Systems in Indonesia,” J. Huk. Nov., vol. 10, no. 2, pp. 150-163, 2019.

[8] H. Baber, "FinTech, Crowdfunding and Customer Retention in Islamic Banks," Vision, pp. 19, 2019.

[9] N. S. Imaniyati, N. Nurhasanah, and T. Tohir, "The Concept of Contract in Financial 
Technology Era Connected with Sharia Principles,” Opcion, vol. 35, no. 24, pp. 10581073, 2019.

[10] R. A. E. Wahyuni, "Perkembangan Ekonomi Islam di Indonesia Melalui Penyelenggaraan Fintech Syariah,” Mahkamah J. Kaji. Huk. Islam, vol. 4, no. 2, pp. 184-192, 2019.

[11] A. B. Alwi, "Pembiayaan Berbasis Teknologi Informasi ( Fintech ) yang Berdasarkan Syariah," Al-Qanun, vol. 21, no. 2, 2018.

[12] M. Mujahidin, "Opportunities and Challenges of Sharia Technology Financials in Indonesia," Munich Pers. RePEc Arch., 2019.

[13] B. N. Asiyah, Manajemen Pembiayaan Bank Syariah. Yogyakarta: Kalimedia, 2014.

[14] B. P. Fawzi, M. Iqbal, and S. Riyadi, "Potensi Finansial Teknologi Syariah dalam Menjangkau Pembiayaan Non-Bank," Al-Masraf (Jurnal Lemb. Keuang. dan Perbankan), vol. 4, no. 2, 2019.

[15] E. A. Firmansyah and M. Anwar, "Islamic Financial Technology (Fintech): Its Challenges and Prospect," Adv. Soc. Sci. Educ. Humanit. Res., vol. 216, no. January, 2018.

[16] H. B. Firmansyah and A. L. Ramdani, "The Role of Islamic Financial Technology ( FinTech ) Start-up in Improving Financial Inclusion in Indonesia Case : Angsur," in The 3rd International Conference of Integrated Intellectual Community, 2018, no. April.

[17] I. Saba, R. Kouser, and I. S. Chaudhry, "FinTech and Islamic Finance-Challenges and Opportunities,” Rev. Econ. Dev. Stud., vol. 5, no. 4, pp. 581-590, 2019.

[18] D. E. Subekti, "Wawancara." Sidoarjo, 2019.

[19] B. M. Indonesia, "Produk Pembiayaan," Bank Mu'amalat Indonesia, 2020. [Online]. Available: https://www.bankmuamalat.co.id/pembiayaan-consumer/kpr-ib-muamalat. 